\title{
Improvement in functional gait parameters following corrective thoracolumbar surgery in children affected by Mucopolysaccharidosis 1(Hurler syndrome)
}

Rajkumar Sundarapandian ( $\nabla$ rkzzwig@gmail.com )

Salford Royal NHS Foundation Trust https://orcid.org/0000-0002-0876-1387

\section{Simon Jones}

Royal Manchester Children's Hospital

Alexander Broomfield

Royal Manchester Children's Hospital

Pauline Hensman

Royal Manchester Children's Hospital

Neil Oxborrow

Royal Manchester Children's Hospital

\section{Research}

Keywords: Mucopolysaccharidosis 1, gait, kyphosis, spinal surgery, functional outcome

Posted Date: January 10th, 2020

DOI: https://doi.org/10.21203/rs.2.20560/v1

License: (c) (i) This work is licensed under a Creative Commons Attribution 4.0 International License.

Read Full License

Version of Record: A version of this preprint was published at Orphanet Journal of Rare Diseases on June 5th, 2020. See the published version at https://doi.org/10.1186/s13023-020-01427-3. 


\section{Abstract}

\section{Objective}

Thoracolumbar kyphosis is a common indication for spinal surgery in children with Mucopolysaccharidosis. Functional outcome of spinal surgical intervention has never been published in patients with this rare disease. We present a cohort of patients with Mucopolysaccharidosis 1(Hurler syndrome) who underwent thoraco-lumbar spinal deformity correction and functional outcome assessed by pre-operative and post-operative gait analysis. This study represents the first attempt at presenting a functional assessment of surgical outcome in any Mucopolysaccharidosis subtype.

\section{Methods}

A retrospective analysis of prospectively collected data was carried out from 11 children diagnosed with this subtype of Mucopolysaccharidosis. All patients underwent thoracolumbar kyphosis correction between the years 2013 to 2016 . Gait assessment was performed using GAITRite ${ }^{\mathrm{TM}}$ electronic walkway pre-operatively and post-operatively within 9 to 24 months from the index surgery. Walking distance, cadence and gait velocity were the three spatio-temporal parameters analysed. Wilcoxon signed rank test was used to analyse the data and P-Value $£ 0.05$ was deemed significant.

\section{Results}

There was a statistically significant improvement in walking distance in 9 out of 11 patient postoperatively with a mean increase of $232.06 \mathrm{cms}(P=0.05)$. There was marginal improvement in cadence by 6.33 steps/min post-operatively (P-value 0.79 ). Gait velocity also showed a marginal increase by 8.73 $\mathrm{cms} / \mathrm{sec}$ post-operatively (P-value 0.32 ).

\section{Conclusion}

The results of our study suggest that correction of thoracolumbar kyphosis in children with Mucopolysaccharidosis 1 resulted in a significant improvement of walking distance with a trend towards improved gait in the other parameters. Post-operative change in cadence was not statistically significant suggesting that physiological maturation of gait had minimal effect in the specified post-operative assessment timeframe. This study emphasizes that outcomes of spinal surgery in children with Mucopolysaccharidosis 1 should be determined by functional measures aiming to maintain or improve quality of life.

\section{Introduction}

Mucopolysaccharidosis 1(MPS1) or Hurler syndrome is a rare autosomal recessive disorder which results in a deficiency of lysosomal enzyme a-L-iduronidase ${ }^{1}$. This leads to failure in the degradation of glycosaminoglycans and their accumulation in various systems of the body. The global incidence of 
MPS 1 was reported as 1 in 100,000 live births ${ }^{2}$. The incidence of MPS 1 in England and Wales was 1.07 per 100,000 live births ${ }^{3}$.

The commonest skeletal manifestations are thoracolumbar kyphosis, hip dysplasia and genu valgum ${ }^{4}$ and these persist despite disease modifying therapies ${ }^{5}$. MPS 1 exists on a spectrum with severe mutations in IDUA leading to complete enzyme deficiency and more rapidly progressive disease. Standard of care for this phenotype of MPS 1 is Haematopoietic stem cell transplantation (HSCT).

Surgical interventions to address dysostosis multiplex in this cohort of patients are associated with high risk and must be justified on clinical grounds and clear indication. Functional outcome measures should determine the overall response to surgical intervention, yet reported outcomes in literature commonly focus on radiological measures. There are no studies which report functional outcome before and after spinal surgery for thoracolumbar kyphosis ${ }^{6}$. Radiological outcome alone in insufficient to assess functional improvement after corrective spinal surgery in this cohort of patients. Surgery to correct thoracolumbar kyphosis is indicated considering the progression of deformity and its flexibility, presence of symptoms, growth potential and co-morbidities ${ }^{7}$ in this group of patients. We present a retrospective cohort study of homogenous patients with severe MPS 1 post HSCT who underwent correction of thoracolumbar kyphosis (Figure 1 and Figure 2) and functional outcome assessed by pre-operative and post-operative gait analysis. This study represents the first attempt at presenting a functional assessment of surgical outcome in any MPS subtype.

\section{Methodology And Research Design}

The objective of our study was to assess gait using validated measures in children with MPS1 before and after correction of thoracolumbar kyphosis. There are over 70 children diagnosed with MPS1 being actively followed up at structured MPS clinics in our hospital. At each visit, gait assessment of all these children is recorded as routine clinical practise. This cohort of children includes those with spinal deformity under surveillance as well as those who have undergone correction of thoracolumbar kyphosis. Thoracolumbar kyphosis is serially assessed and surgically intervened based on the progression of deformity, its flexibility, presence of symptoms, growth potential and co-morbidities ${ }^{7}$. All the children who underwent correction of thoracolumbar kyphosis were operated by a single senior Paediatric Spinal Surgical Consultant.

A retrospective analysis of prospectively collected gait data was undertaken of MPS1 patients who underwent thoracolumbar kyphosis correction between the years 2013 to 2016 in our centre. A total of 11 patients were identified and included in the study, out of which 9 patients had single stage Posterior spinal deformity correction and 2 patients had undergone Anterior release followed by Posterior spinal deformity correction. All patients had completed atleast 9 months following surgery and were capable of walking independently. There were 5 male and 6 female patients, aged 5 - 13 years (mean 9.27 years) at the time of surgery in the study group (Table 1). The post-operative gait assessment in months from the index surgery ranged from 11 to 35 months (mean 18.45 months). 
Table 1: Patient demographics with age at time of stem cell transplant, age at time of surgery and month at which post-operative gait assessment was done.

\begin{tabular}{|l|l|l|l|l|}
\hline Patient & Gender & $\begin{array}{l}\text { Age at the time of } \\
\text { transplant in } \\
\text { months }\end{array}$ & $\begin{array}{l}\text { Age at the time } \\
\text { of surgery in } \\
\text { years }\end{array}$ & $\begin{array}{l}\text { Post-operative gait } \\
\text { assessment in months after } \\
\text { surgery }\end{array}$ \\
\hline 1. & Male & 15 months & 10 years & 28 months \\
\hline 2. & Female & 10 months & 9 years & 14 months \\
\hline 3. & Female & $\begin{array}{l}1^{\text {st }}-11 \text { months } \\
2^{\text {nd }}-16 \text { months }\end{array}$ & 11 years & 13 months \\
\hline 4. & Female & $\begin{array}{l}1^{\text {st }}-11 \text { months } \\
2^{\text {nd }}-19 \text { months }\end{array}$ & 13 years & 16 months \\
\hline 5. & Female & 12 months & 10 years & 18 months \\
\hline 6. & Female & 9 months & 11 years & 16 months \\
\hline 7. & Female & 14 months & 9 years & 11 months \\
\hline 8. & Male & 8 months & 5 years & 24 months \\
\hline 9. & Male & 12 months & 7 years & 17 months \\
\hline 10. & Male & 8 months & 7 years & 35 months \\
\hline 11. & Male & 20 months & 10 years & 11 months \\
\hline
\end{tabular}

\section{Gait assessment}

Gait analysis was performed using the GAITRite ${ }^{\text {TM }}$ system during each clinic visit.

Each child was made to walk the length of the walkway back and forth, without footwear or orthosis at a self-selected speed for one minute. GAITRite ${ }^{\mathrm{TM}}$ electronic walkway is a mat embedded with sensor pads to measure spatial and temporal parameters of gait. Multiple interconnected sensor pads form the length of the walkway on which subjects walk. The pressure sensitive sensors activate to sense geometry of the object, relative arrangement between them in a two-dimensional space and vertical component of the pressure exerted by the object. When the subject walks across the walkway (Figure 3), footprints are obtained as quadrilaterals in real time with information on relative arrangement with the opposite feet ${ }^{8}$. Each walk of the subject is recorded in a laptop which is connected to the walkway. We analysed cadence, gait velocity and walking distance of all the children included in the study group. 
The closest pre-operative assessment was selected along with the post-operative assessment recorded between 9 to 24 months. The latter time frame was chosen to allow recovery from surgery and also minimise any potential confounding progression of lower limb disease affecting gait.

\section{Ethical considerations}

This study did not require Research ethics approval or Health Research Authority clearance as per the Research and Innovation Department of the hospital. Gait assessment in these children is performed as routine clinical practise on every attendance to the MPS clinic. We accessed previously recorded gait analysis data which did not affect clinical practise. The data we extracted for assessment was handled as per Information governance guidelines. Informed verbal consent was taken as standard practise from the parent or guardian of each child before gait assessment. All procedures followed were in accordance with Helsinki declaration.

\section{Statistical analysis}

Statistical analysis was performed using SPSS software. Shapiro-Wilk test was used to determine that the data was not normally distributed. Comparison of median values of two related samples (preoperative and post-operative measurements) was undertaken using the Wilcoxon signed rank test (nonparametric test). A two-tailed hypothesis with a P-value of $£ 0.05$ was deemed significant.

\section{Results}

The pre-operative and post-operative gait assessment data (Table 2) of the 11 patients were analysed.

Table 2: Pre-operative and post-operative gait assessment data of all children included in the study. 


\begin{tabular}{|l|l|l|l|l|l|l|}
\hline Patient & $\begin{array}{l}\text { Pre-op } \\
\text { nalking } \\
\text { distance } \\
(\mathrm{cm})\end{array}$ & $\begin{array}{l}\text { Post-op } \\
\text { walking } \\
\text { distance } \\
(\mathrm{cm})\end{array}$ & $\begin{array}{l}\text { Pre-op } \\
\text { cadence } \\
\text { (steps/unit } \\
\text { time) }\end{array}$ & $\begin{array}{l}\text { Post-op cadence } \\
\text { (steps/unit time) }\end{array}$ & $\begin{array}{l}\text { Pre-op } \\
\text { velocity } \\
\text { (cm/sec) })\end{array}$ & $\begin{array}{l}\text { Post-op } \\
\text { velocity } \\
\text { (cm/sec) }\end{array}$ \\
\hline 1 & 1324.24 & 1325.53 & 94.1 & 98.8 & 74.2 & 70.4 \\
\hline 2 & 1105.28 & 1344.74 & 140.1 & 133.5 & 80.2 & 99.8 \\
\hline 3 & 2183.57 & 1636.79 & 114.8 & 109.4 & 88.9 & 99.4 \\
\hline 4 & 1319.31 & 1308.11 & 128.9 & 139.5 & 118.1 & 118.4 \\
\hline 5 & 1802.64 & 2019.6 & 145.7 & 138 & 95.2 & 145.2 \\
\hline 6 & 1219.14 & 1749.55 & 129 & 126.6 & 124.8 & 99.8 \\
\hline 7 & 766.26 & 1399.07 & 118.5 & 204.9 & 89 & 103.9 \\
\hline 8 & 933.23 & 1523.57 & 152.7 & 114.5 & 99 & 70.9 \\
\hline 9 & 893.01 & 1367.53 & 159.4 & 120.6 & 107.9 & 88.7 \\
\hline 10 & 1670.63 & 1831.94 & 146.1 & 169.9 & 101.7 & 140.2 \\
\hline 11 & 872.15 & 1135.77 & 103.3 & 146.5 & 68.2 & 106.6 \\
\hline
\end{tabular}

Box and whisker plot was used to analyse distributional characteristics of the group of scores and the level of scores. The most significant observations were made when pre-operative and post-operative walking distance (Figure 4) was compared. The median (dark purple line inside the box) or middle quartile of preop walking distance was $1219.14 \mathrm{cms}$ and showed a significant increase to $1399.07 \mathrm{cms}$ postoperatively. The inter-quartile range is represented by the middlebox containing the middle $50 \%$ of the scores. The preop inter-quartile range was equally divided by the median, while the postoperative interquartile range was unequally divided by the median. The postop interquartile range showed a significant overall increase. The data points in the graph denotes 7 out of 11 patients clustered within the interquartile range postoperatively. It is also to be noted that 5 out of 11 patients clustered close to the median postoperatively, while they were widely distributed in relation to the median pre-operatively. The visible shortening of the postop inter-quartile range box with clustering of data points close to the median is reflected by statistically significant increase of walking distance postoperatively $(p=0.05$, Wilcoxon signed rank). Walking distance increased by a mean of $232.06 \mathrm{~cm}$ post-operatively. The outliers in the lower whisker and upper whisker remained far from the median but showed proportionate improvement postoperatively. 
The median of pre-op cadence was 129 and post-op cadence was 133.5. There was a marginal increase in cadence post-operatively (Figure 5). There was no clustering of data points in the interquartile range. Change in post-op cadence was not statistically significant ( $p$-value 0.79 , Wilcoxon signed rank).

Gait velocity also showed a marginal increase post-operatively (Figure 5) and therefore was similar to cadence on the box and whisker plot. The median of pre-op gait velocity was $95.2 \mathrm{cms} / \mathrm{sec}$ and post-op gait velocity was $99.8 \mathrm{cms} / \mathrm{sec}$. Gait velocity increased by $8.73 \mathrm{cms} / \mathrm{sec}$ postoperatively and was not statistically significant ( $p$-value 0.32 , Wilcoxon Signed Rank).

\section{Discussion}

Hurler syndrome was first described to predominantly involve the skeletal system ${ }^{9}$. Dysostosis multiplex refers to the complex of orthopaedic abnormalities resulting due to defective membranous and endochondral growth ${ }^{10}$. The effect of these orthopaedic abnormalities on locomotor ability of the affected child is profound. Children with Mucopolysaccharidosis 1 have below average gross motor abilities ${ }^{11}$ and delayed maturation of gait ${ }^{12}$. Orthopaedic abnormalities including thoracolumbar kyphosis in this group can be progressive and surgical intervention may be justified. Thoracolumbar kyphosis with a Cobb's angle of more than 40 degrees in children with Hurler syndrome is most likely to progress ${ }^{13}$. Our justification for spinal surgical intervention in this cohort of patients is based on clinical practise guidelines by International consensus procedure developed using a modified Delphi approach ${ }^{7}$ with the eventual goal of treatment is to maintain or improve the quality of life.

There are seven types of Mucopolysaccharidosis and three subtypes of Mucopolysaccharidosis 1 (AHurler syndrome, B-Hurler-Scheie syndrome and C-Scheie syndrome). This study is the first attempt to assess functional outcome after Spinal deformity correction in patients with MPS of any subtype. Data obtained from GAITRite ${ }^{T M}$ electronic walkway assessed spatio-temporal parameters of gait in this group of children before and after correction of thoracolumbar kyphosis. GAITRite ${ }^{\mathrm{TM}}$ walkway has been proven to have good reliability with immediate re-test, 2 week re-test and Intraclass correlation coefficients $>0.75$ for measuring spatio-temporal parameters of gait ${ }^{14}$ along with strong concurrent validity ${ }^{15}$.

The nearest pre-operative and post-operative gait assessment data within 9 to 24 months of the index surgery were used for analysis. Children were found to be recovering from the index spinal surgery when assessed within 9 months of surgery. Therefore, time was given for the child to recover from the spinal surgery and then gait assessment was done. After 24 months there was a possibility of deterioration of gait due to the progression of disease in the hip and knee joints affecting global locomotor ability.

Physiological maturation of gait is another potential confounding variable in growing children. Gait in the MPS study group may be expected to mature more slowly than the unaffected child. Restricting the post op assessment time frame to 9 months to 24 months helps us identify changes in the gait which can be attributed to spinal surgery and not due to physiological development. Gait analysis data of one patient alone was obtained 35 months after index spine surgery as that was the only available post-operative assessment data for that patient. 
Walking distance is a good indicator of the overall ability of bipedal locomotion to propel the body from point $A$ to point $B$. Walking distance or distance travelled on the walkway is measured in centimetres on the horizontal axis from heel centre of first foot print to the heel centre of last foot print ${ }^{8}$. It is not affected by the disease process in the joints of the lower extremities or individual footfalls. Parameters such as stance phase can be affected if the disease process has resulted in antalgic gait from an affected hip joint. Similarly, step length can be recorded as a negative value if the child fails to bring the landing foot heel point forwards of the stationary foot making parameters of individual footfalls unreliable. Nine out of eleven patients in the study group exhibited a statistically significant increase in walking distance postoperatively (mean postoperative increase of $232.06 \mathrm{cms}$, P-value 0.05 ). There is no literature evidence to standardize normal walking distance according to age in this cohort.

Cadence is calculated as the number of steps taken per minute. Reducing cadence in a growing child is an indicator of maturing gait ${ }^{16}$. All the children in our study were assessed within 9 to 24 months from the index spine surgery, which was a cross-sectional analysis in a surgical cohort and not a linear assessment of gait maturation. We observed that there was a trend towards reduction of cadence postoperatively in six out of the eleven patients in the study group, which was not statistically significant (P-value 0.79). Therefore, physiological development did not have significant impact on gait during our assessment time frame postoperatively.

Gait velocity was calculated on the walkway after dividing the distance travelled by ambulation time. Measuring gait velocity reflected the ability or the ease with which the children walked after Spinal surgery. Gait velocity in our study increased in seven out of the eleven patients postoperatively. However, the mean increase in gait velocity by $8.73 \mathrm{cms} / \mathrm{sec}$ postoperatively was also not statistically significant (P-value 0.32 ). Cadence and gait velocity showed only a marginal improvement postoperatively.

Sagittal spinal curvatures help in maintaining global sagittal spinal balance and aid bipedal locomotion. A balanced spine requires minimal muscular effort to maintain an upright posture. Thoracolumbar kyphosis alters spinal biomechanics by resulting in an anterior shift of the truncal mass with increased flexion moment arm. An increased sagittal spinal curvature with increased flexion moment arm alters physiological loading of compression and shear forces across spinal segments ${ }^{17}$. Thoracolumbar kyphosis renders the normally strong dorsal extensor paraspinal musculature weak, affecting the ability to maintain an upright posture. The anterior truncal shift stretches the dorsal extensor paraspinal musculature beyond a point where the length-tension relationship is altered ${ }^{18,19}$.

Compensatory effect of sagittal spinal deformity is commonly observed in the neck and in the lower limbs. A backward tilt of the pelvis, flexion of the knees and dorsiflexion of the ankles are some of those seen in the lower extremity. The effort required for the lower limb to function in conjunction with the compensatory mechanism results in early fatigue with poor exercise tolerance. Children in this cohort have joints in lower extremities affected by the same disease process, adding to the burden of poor gait. Therefore, changes in sagittal spinal balance and poor lower limb function can both affect gait. Surgery to correct thoracolumbar kyphosis in our cohort is an attempt to restore sagittal spinal alignment which 
in turn has shown a functional improvement of gait. The reported improvement of gait in our study was attributed to restoration of sagittal spinal alignment as none of the children in the study group had any intervention to address the disease process in the joints of lower extremities within the post-operative assessment timeframe. Three children in our study group had hemiepiphysiodesis of knee joint done more than year before the index spinal surgical intervention. This will not have any impact on our study as we have taken the nearest pre-operative gait assessment as baseline.

The process of maturation of gait in children with Mucopolysaccharidosis 1 is delayed when compared to normally developing children ${ }^{11}$. Improvement in cadence postoperatively was not statistically significant proving that physiological maturation had minimal effect on gait in the post-operative assessment timeframe. Therefore, the trend towards improved gait observed within the postoperative window (9 to 24 months) was due to surgical correction of the spinal deformity rather than developmental maturation of gait. Within the limitations of our study we were able to obtain statistically significant results in one out of the three parameters analysed with a study group of 11 patients. A larger sample size may yield significant results in other parameters as well. HhHowever, we do reflect the population of the largest centre for treatment of severe MPS1 in Europe and multi centre studies of surgical outcomes have proven challenging due to the variability in indication and procedure used in this group.

\section{Conclusion}

The results of our study suggest that children with MPS1 who had Surgical correction of thoracolumbar kyphosis exhibited a trend towards improved gait after surgery. There was a statistically significant increase in the walking distance post-operatively with a trend towards improved cadence and gait velocity. The limitation of 9 to 24 months in the post-operative period ensured that our gait assessment was not affected by the physiological changes in gait or the disease process in joints of lower extremities.

\section{Declarations}

\section{Contribution of individual authors-}

1.Dr Rajkumar Sundarapandian- Primary author who was involved in gait assessment, data collection, analysis and writing up this paper.

2.Dr Simon Jones- Second author who provided suggestions regarding structure of this paper,provided input from medical perspective of this condition and reviewed these patients in structured MPS clinic at each visit.

3.Dr Alexander Broomfield- Third author who provided suggestions regarding structure of this paper,provided input from medical perspective of this condition and reviewed these patients in structured MPS clinic at each visit. 
4.Pauline Hensman- Fourth author and our Specialist Physiotherapist who performed the gait analysis in all patients to accumulate data in the clinics.

5.Mr Neil Oxborrow-Senior author and Consultant Paediatric Spinal Surgeon, who had performed the surgeries on all patients included in the study. He was involved in reviewing every aspect of this study from its conception to conclusion.

\section{Name of corresponding author and guarantor-}

Dr Rajkumar Sundarapandian

\section{Declaration of competing interest-}

There is no competing interest to declare

\section{Details of funding-}

There was no funding received to perform this study

\section{Details of ethics approval-}

This study did not require ethics committee approval and this was confirmed by the Research and Innovation Department of the Royal Manchester Children's Hospital, where the study took place.

\section{Patient consent statement-}

Verbal consent was obtained from the parent/guardian of each child before they were made to walk on the walkway for gait assessment. This has been routine clinical practise at the MPS clinic. The data obtained was handled as per Information governance policy

\section{Consent for publication-}

Obtained

\section{Availability of data-}

All relevant data used in this study has been included in the manuscript. The corresponding author can be contacted if any further information is needed.

\section{References}

1. Bach G, Friedman R, Weissmann B, Neufeld EF. The defect in the Hurler and Scheie syndromes: deficiency of a-L-iduronidase. Proceedings of the National Academy of Sciences. 1972 Aug $1 ; 69(8): 2048-51$. 
2. Beck M, Arn P, Giugliani R, Muenzer J, Okuyama T, Taylor J, Fallet S. The natural history of MPS I: global perspectives from the MPS I Registry. Genetics in Medicine. 2014 Oct;16(10):759.

3. Moore D, Connock MJ, Wraith E, Lavery C. The prevalence of and survival in Mucopolysaccharidosis I: Hurler, Hurler-Scheie and Scheie syndromes in the UK. Orphanet journal of rare diseases. 2008 Dec;3(1):24.

4. White KK. Orthopaedic aspects of mucopolysaccharidoses. Rheumatology. 2011 Dec 1;50(suppl_5):v26-33.

5. Aldenhoven M, Boelens J, de Koning TJ. The clinical outcome of Hurler syndrome after stem cell transplantation. Biology of Blood and Marrow Transplantation. 2008 May 1;14(5):485-98.

6. Williams N, Challoumas D, Eastwood DM. Does orthopaedic surgery improve quality of life and function in patients with mucopolysaccharidoses?. Journal of children's orthopaedics. 2017 Aug 1;11(4):289-97.

7. Kuiper GA, Langereis EJ, Breyer S, Carbone M, Castelein RM, Eastwood DM, Garin C, Guffon N, Van Hasselt PM, Hensman P, Jones SA. Treatment of thoracolumbar kyphosis in patients with mucopolysaccharidosis type I: results of an international consensus procedure. Orphanet journal of rare diseases. 2019 Dec;14(1):17.

8. Inc CS. GAITRite electronic walkway technical reference manual.

9. Hurler G. Über einen Typ multipler Abartungen, vorwiegend am Skelettsystem. European Journal of Pediatrics. 1920 Jan 10;24(5):220-34.

10. Field RE, Buchanan JA, Copplemans MG, Aichroth PM. Bone-marrow transplantation in Hurler's syndrome. Effect on skeletal development. The Journal of bone and joint surgery. British volume. 1994 Nov;76(6):975-81.

11. Dusing SC, Thorpe D, Rosenberg A, Mercer V, Escolar ML. Gross motor abilities in children with Hurler syndrome. Developmental medicine and child neurology. 2006 Nov;48(11):927-30.

12. Dusing SC, Thorpe DE, Mercer VS, Rosenberg AE, Poe MD, Escolar ML. Temporal and spatial gait characteristics of children with Hurler syndrome after umbilical cord blood transplantation. Physical therapy. 2007 Aug 1;87(8):978-85.

13. Siddique I, Sacho R, Oxborrow NJ, Wraith JE, Williamson JB. Thoracolumbar Kyphosis in Mucopolysaccharidosis I (Hurler Syndrome). InOrthopaedic Proceedings $2010 \mathrm{Jul}$ (Vol. 92, No. SUPP_III, pp. 427-427). The British Editorial Society of Bone \& Joint Surgery.

14. Gretz HR, Doering LL, Quinn J, Raftopoulos M, Nelson AJ, Zwick DE. Functional ambulation performance testing of adults with Down syndrome. NeuroRehabilitation. 1998 Jan 1;11(3):211-25.

15. Bilney B, Morris M, Webster K. Concurrent related validity of the GAITRite ${ }^{\circledR}$ walkway system for quantification of the spatial and temporal parameters of gait. Gait \& posture. 2003 Feb 1;17(1):6874.

16. Sutherland DH, Olshen RI, Cooper L, Woo SL. The development of mature gait. J Bone Joint Surg Am. 1980 Apr 1;62(3):336-53. 
17. Pearsaii DJ, Reid JG. Line of gravity relative to upright vertebral posture. Clinical Biomechanics. 1992 May 1;7(2):80-6.

18. Tveit $P$, Daggfeldt $K$, Hetland $S$, Thorstensson A. Erector spinae lever arm length variations with changes in spinal curvature. Spine. 1994 Jan;19(2):199-204.

19. McGill SM, Hughson RL, Parks K. Changes in lumbar lordosis modify the role of the extensor muscles. Clinical Biomechanics. 2000 Dec 1;15(10):777-80.

\section{Figures}




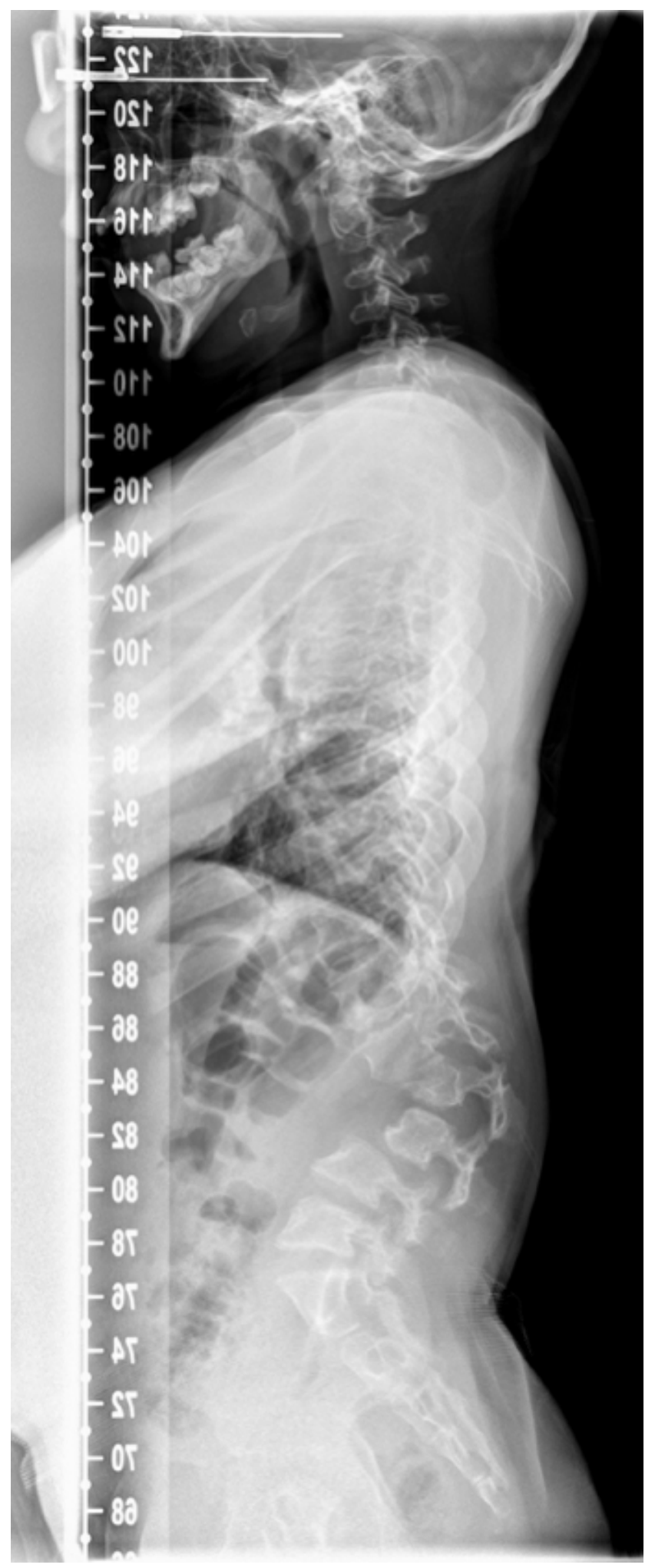

\section{Figure 1}

Pre-operative radiograph of thoracolumbar spine showing high lumbar kyphosis- Lateral view 


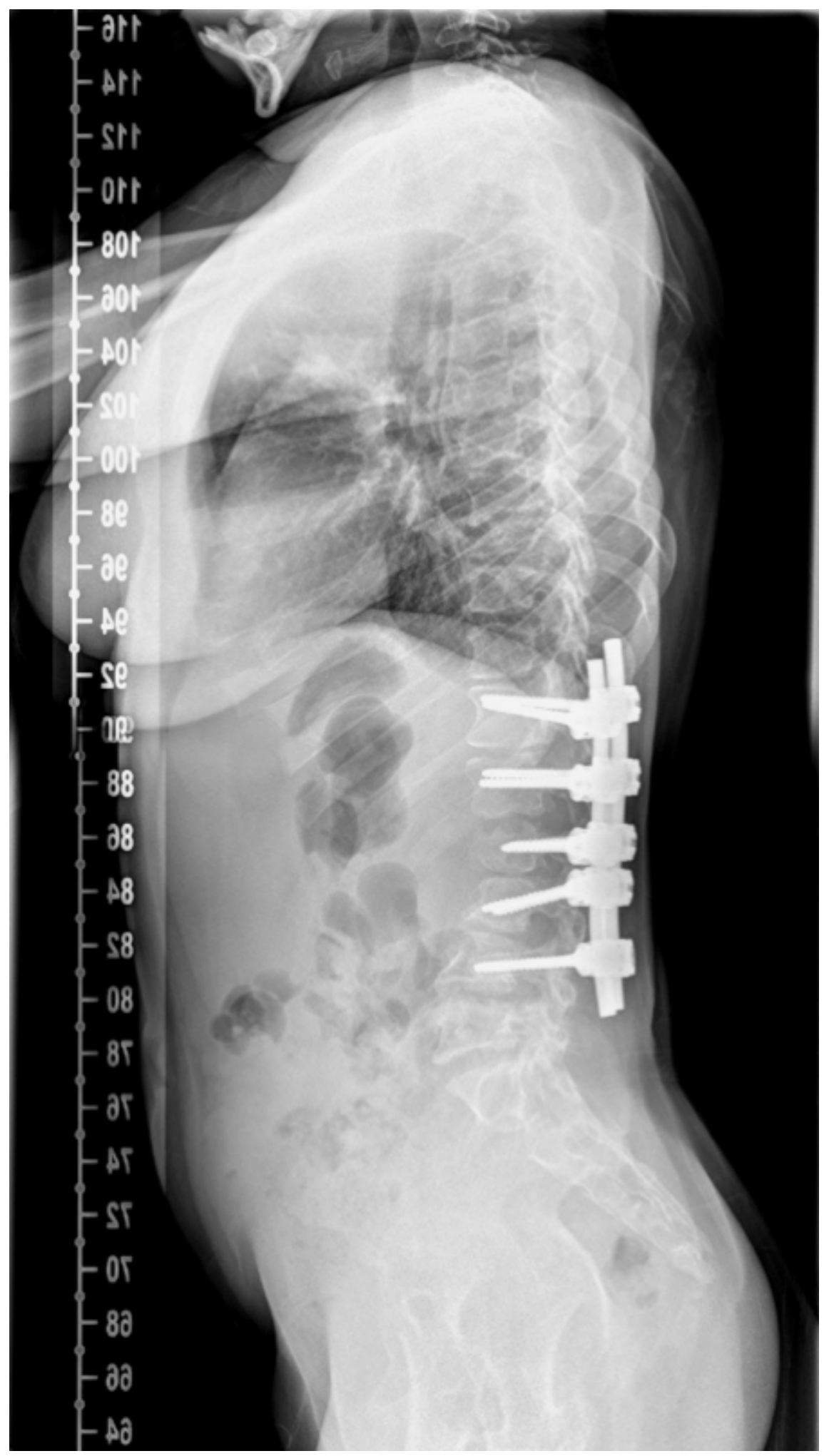

Figure 2

Post-operative radiograph of the same patient after correction of thoracolumbar kyphosis- Lateral view 


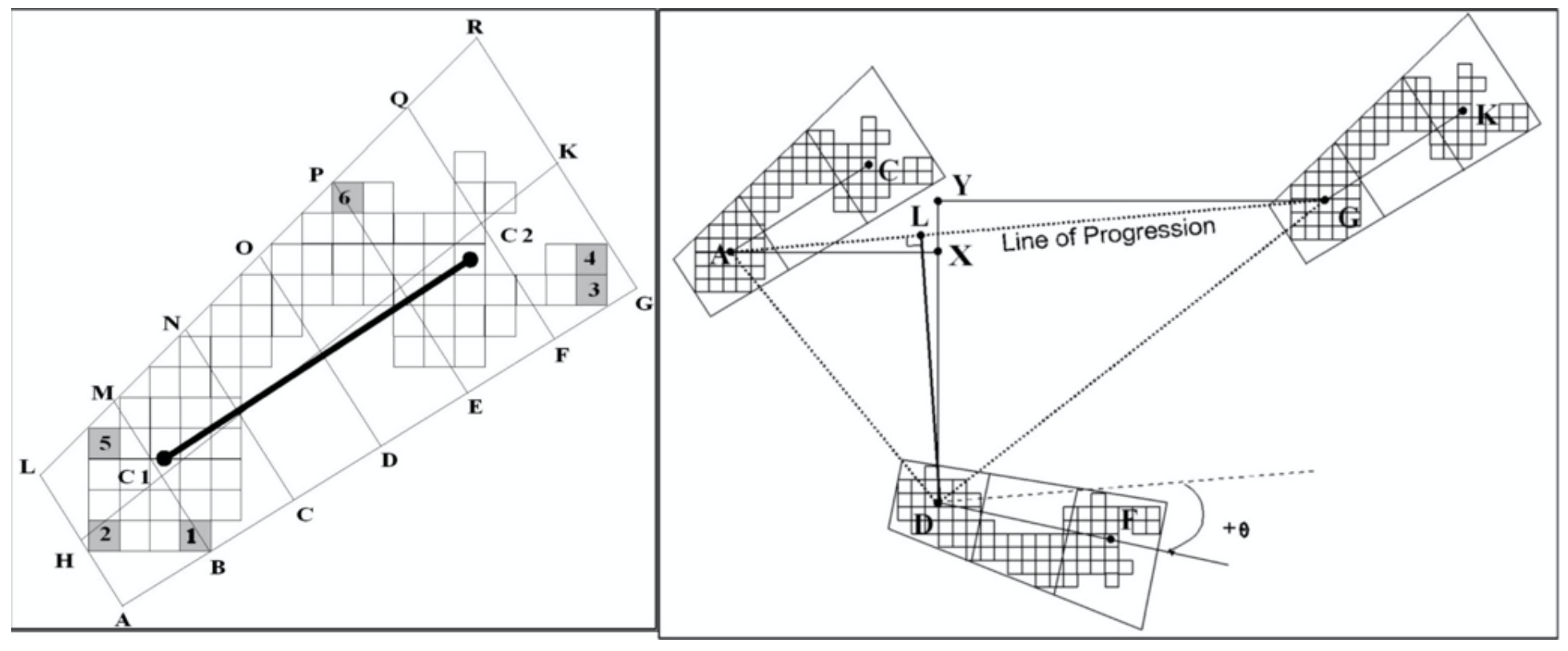

Figure 3

Identification of quadrilaterals, midline of foot and the line of progression using the walkway- Image reproduced with permission from CIR Systems, Inc. GAITRite Electronic walkway technical reference (WI02-15. Rev L 5/6/2013) 


\section{Walking distance}
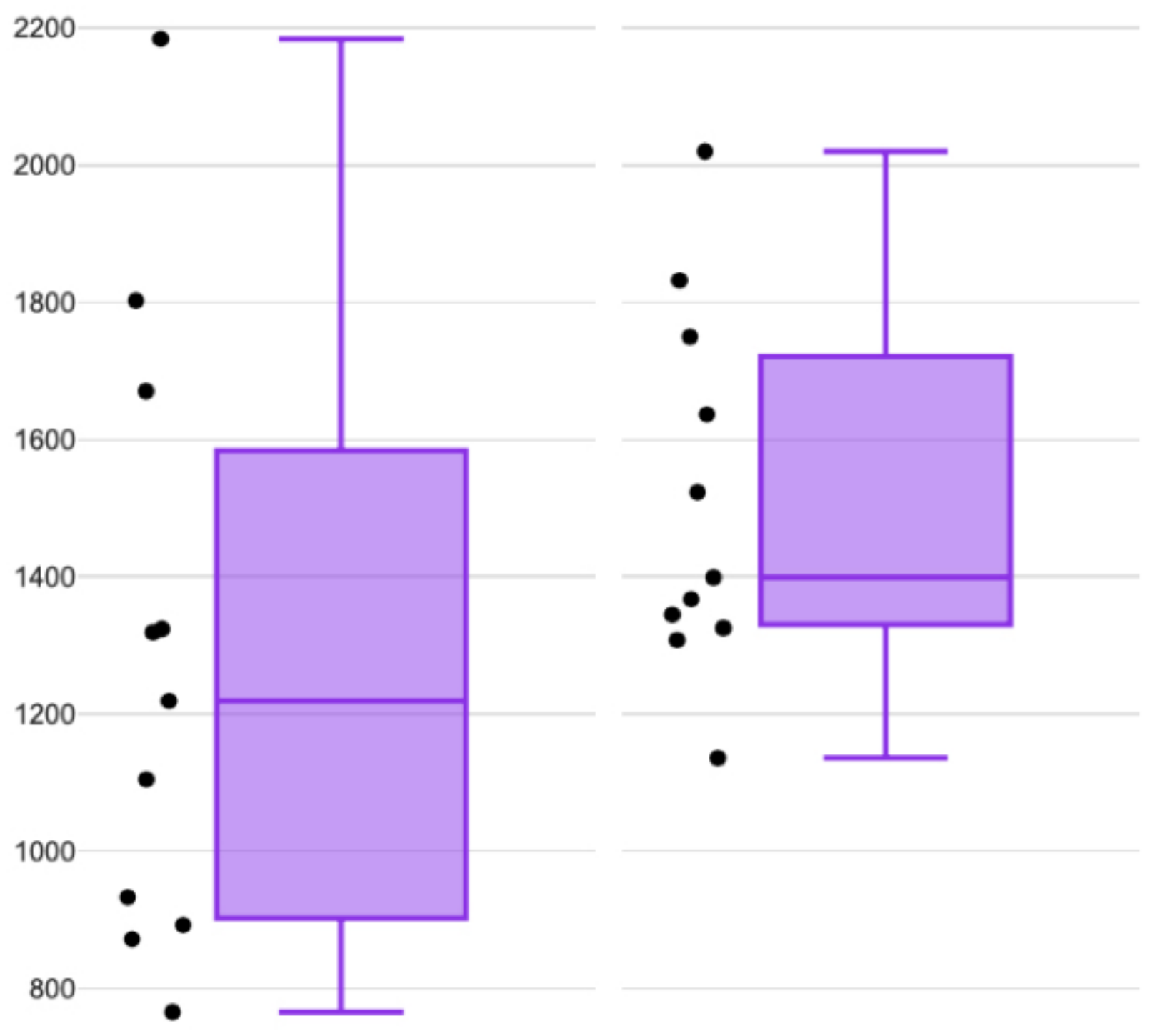

Pre op Walking

Post op Walking

distance (cms) distance (cms)

Figure 4

Box and Whisker plot comparing pre-operative and post-operative walking distance $(\mathrm{cms})$ 


\section{Cadence \& Gait velocity}

200

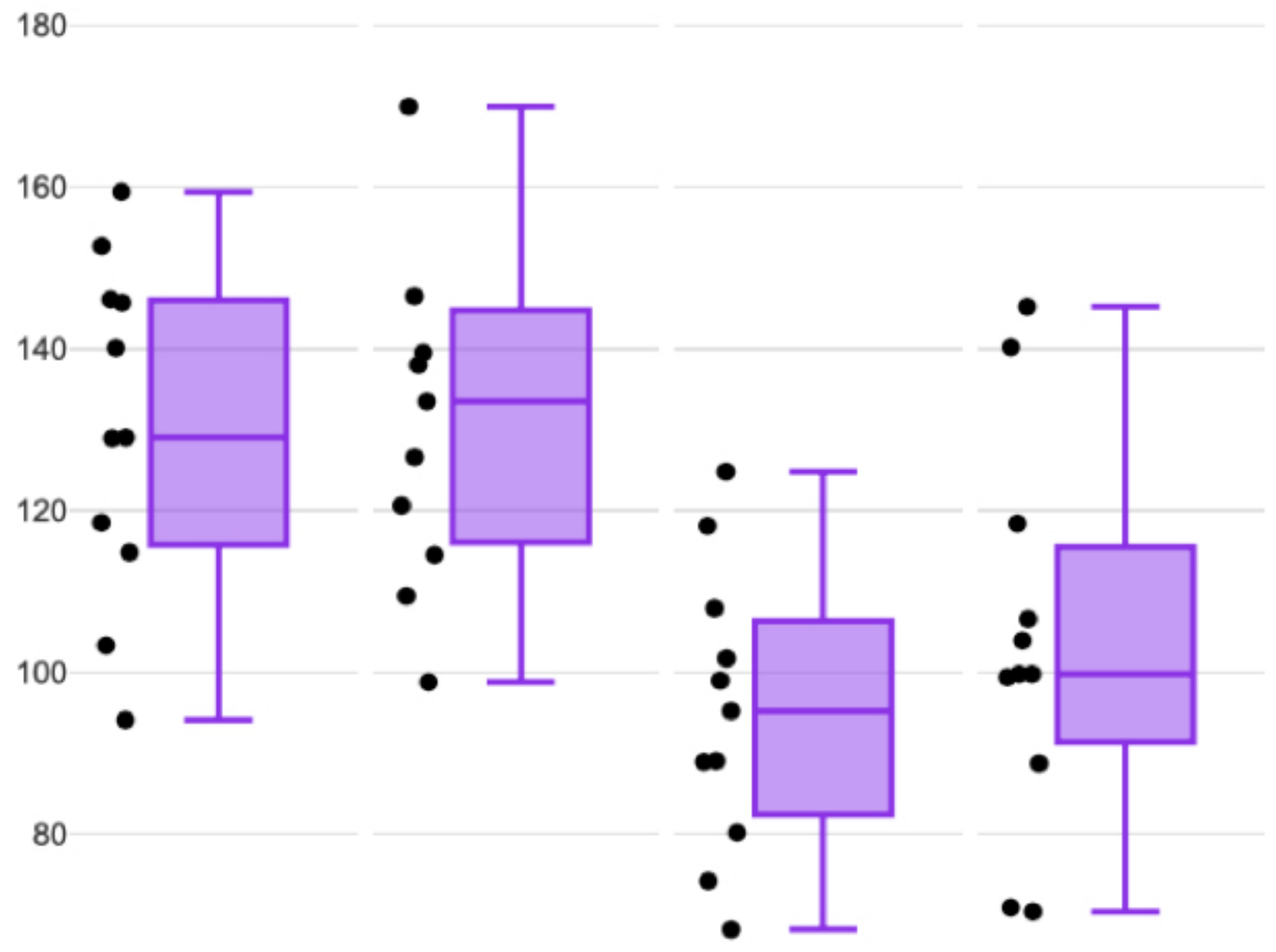

Pre op Cadence Post op Cadence Pre op Gait velocity Post op Gait velocity

Figure 5

Box and Whisker plot comparing pre-operative and post-operative cadence(steps/min) and gait velocity $(\mathrm{cms} / \mathrm{sec})$ 